\title{
Dwell Time Analysis and Priority Granting for Bus Service in Budapest
}

\author{
Souhir Boudhrioua1*, Tibor Sipos ${ }^{1}$ \\ ${ }^{1}$ Department of Transport Technology and Economics, Faculty of Transportation Engineering and Vehicle Engineering, Budapest \\ University of Technology and Economics, H-1111 Budapest, Múegyetem rkp. 3., Hungary \\ * Corresponding author, e-mail: souhir.boudhrioua@edu.bme.hu
}

Received: 10 May 2020, Accepted: 08 July 2020, Published online: 10 February 2022

\begin{abstract}
Public transport has always been a structuring factor in urban development and form. Buses, which are one of the essential public services, do not require expensive infrastructure, can be introduced quickly and run as frequently as necessary to meet the demand. Budapest is known by the diversity of its transportation modes and their high frequency, nevertheless, it still faces traffic congestion issues. Thus, the priority granting for the buses is essential to minimize the travel time delays.

This research analysis investigates the bus service's situation on the chosen corridor based on personal data collection in peak-hours at the bus stops and on-board using GPS tracker.

This research aims to study the dwelling bus's impact on car delays and targets to optimize the situation by implementing bus priority. The iterative models coded with Octave calculates the vehicles' delays function of the arrival time and dwelling time of the bus and analyses all scenarios depending on the time the bus is ready to leave the stop and adjusting it by either holding the bus at bus stops or allowing an immediate departure with speed adjustment or green light extension.

The objective of the proposed priority model is not only to minimize the bus delays, but also the average vehicle delays on the different branches of the intersection. The prioritization system takes into consideration the non-violation of the maximum holding time, maximum green time extension and maximum red time in the intersection's branches where the bus stop exists.
\end{abstract}

\section{Keywords}

bus priority, dwell time, car delays

\section{Introduction}

Congestion represents one of the crucial problems mainly all the cities suffer from. Building our way out of the problem by constructing new roads and widening others is not the answer, in most cases, it is physically impossible (Pojani and Stead, 2015). It becomes more problematic and crucial when it comes to narrow roads, where only one lane is available in each direction and especially in the inner cities (Guler et al., 2015). Public transport in Budapest is quite reliable and fast, it represents $45 \%$ of transportation modes and $65 \%$ of the residents used it for the daily transit in 2014 and the two features are estimated to increase to respectively $50 \%$ and $80 \%$ in 2030 (Denke, 2017). Since the 1970s, Budapest's public transport has been based on the metro lines, yet the shortage of the components of the infrastructure and the lack of interoperability force buses to replace, permanently, the track-bound services. Following the steps of the Western European trends, the approach of transport planning has changed on the strategic level by the implementation of livability targeting the cycling infrastructure, the traffic calming, prioritization of public transport, bus lanes' reinstatement and long bus routes (Budapesti Közlekedési Központ, 2013).

Bus service itself is composed of 237 bus lines and 2611 $\mathrm{km}$ of network. The bus fleet in 2014 had $87.9 \%$ of low floor buses and provided $40 \%$ of the seat per kilometer ( 7.66 billion seat $-\mathrm{km}$ ) and $52 \%$ of the vehicle per kilometer (92.5 million vehicle-km). Despite its frequency, it has several problems such as low quality (Denke, 2017).

Several features affect the service such as the stop design that has a significant impact on transit vehicle, on the operations of the intersection and its safety as well as the adjacent properties and the system performance (Transit Cooperative Research Program, 1996). The bus stop location, which can be either before near-side or far-side, the design can have an 
impact on the traffic as some studies have found that the farside stops encounter less overall delays, while the near-side stop may cause more issues (Liu and Jian, 2019).

If the bus stop is already defined, the bus priority would help solve some of the issues and allow to beat queues in known congestion spots, to stop them from being stuck in traffic with all the other vehicles, and to create faster and more reliable journey times (Ahmed, 2014). The bus priority that shall be implemented, is the active priority depending on the policies used in the municipality and on the infrastructure available to detect buses. Mainly, here the traffic lights are more interactive with the presence or the arrival of buses (Oliveira-Neto et al., 2009).

The buses would run faster, the cycle time would be shorter, which results in less number of vehicles, thus less fuel consumption so the operators would achieve lower operational costs. Besides, this would reduce maintenance cost and increase revenues (Kózel, 2017).

The objective of this research is to study the current bus service situation in the corridor between the bus stations of Keleti Pályaudvar and Fő tér for a set number of buses in the city of Budapest, Hungary, both on-board of the bus and in the two delimited bus stops.

This study aims to develop a dwell time model using the data collected during peak hours, which shall be used to improve the overall bus service reliability and efficiency. This includes the investigation of the effect of the dwelling buses on the traffic and on the car delays for each combination of bus arrivals and time in the stop.

Afterwards, in order to improve the provided level of service on the chosen route, the prioritization for the buses and its consequences are tested using coded program realized with the programming language in GNU Octave for numerical computations.

Once the technique show its effectiveness and a promising enhancement in the bus service on the studied corridor, an expansion can be extended for the whole bus lines.

\section{Methodology}

The research is based on the analysis of the data collected personally. Thus, first of all, the measurements are realized on-board using the GPS tracker OSMAnd application between the bus stops Fö tér and Keleti Pályaudvar and at the bus stops during the peak hours on weekdays. Second, the data are examined to determine the different features of the bus service in the corridor such as the bus's overall speed, the loss time, boarding/alighting time, running time, dwell time, time wasted at the traffic light ...
Then, the third part targets to deeply analyze, on the one hand, the effect of the dwelling bus in the stop on the vehicles present in the intersection. On the other hand, the priority allocation for the bus service and testing it with the measured parameters. This work is made based on two iterative models for the dwell time and the priority granting that assess all measurements through programs coded with Octave.

\section{Related works}

The intersections and especially the signalized ones, usually represent a major source for vehicular delays as it involves an interaction between different transportation modes. The bad management of the bus stops near the intersections and the bus dwelling at these stops might lead to the increase of queues and the reduction of the capacity of discharge, which shall create delays not only in one intersection but also in the surrounding ones (Gu et al., 2014).

\subsection{Impact of the bus dwell time on the traffic}

The impact of the prioritization of the buses is important for handling the traffic as the buses cause traffic issues in case they are delayed, or dwelling in the bus stop especially if there is no special platform for the bus stop. The small speed adjustment or lane changing can create platoons, which is deeply studied in the kinematic wave theory models (Gu et al., 2014).

After arriving at the stop at $t_{a^{\prime}}$ as shown in Fig. 1, the dwelling bus in the bus stopping for duration $S$, creates more car queue and persists for a duration of $T_{1}$ during the green time. Then, after the end of the red time the cars in front of the bus discharge and the queue behind the bus persists for $T_{2}$, which is being discharged after the bus departs.

This concept shows the crucial prioritization of the bus service and the consequences, caused by the small delays, on the traffic.

\subsection{Transit Signal Priority}

Usually, the Transit Signal Priority (TSP) is used, at the signalized intersections, in order to give priority to vehicles in public transit, either by increasing the time of green or by decreasing the time of red for the signal phases dealing with the transit vehicles, where transit vehicles designate a large vehicle used to carry passengers such as buses or the light-rail (Shaaban and Ghanim, 2018). However, the TSP systems are unstable and based on the stochastic criteria of the flow (Muñoz et al., 2013) and might even create more traffic issues or the infrastructure does not allow to have extra lane (Gu et al., 2014). 


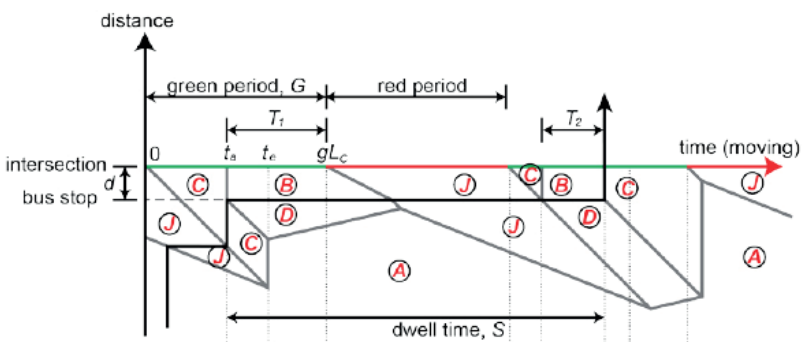

Fig. 1 Time-space diagram of a dwelling bus in the stop (Gu et al., 2014)

\subsection{Traffic light synchronization}

If the infrastructure and the techniques are available, an implementation of an algorithm synchronizing the traffic lights with the use of adaptive traffic control can help for a global optimization approach to achieve a traffic lights configuration that guarantees a sustainable improvement of mobility patterns. (Nesmachnow et al., 2019)

The system can be predictive and help allocate the priority depending on the traffic situation and the emergency if the bus is behind schedule, this requires more sophisticated programs and shall be more useful in the future traffic predictive controllers (Boudhrioua and Shatanawi, 2021).

\subsection{Controlled departure}

The problem buses mainly face is stopping so many times, which implies many drawbacks such as delays, high fuel consumption, pollution .In order to optimize the bus service without interfering in the infrastructure and use the already existing one, several papers studied the controlled departure. As in (Koehler and Kraus, 2006), schemes were designed to reduce the number of stops of the buses, basically for the stops near the intersection. Moreover, the adjustment of the speed of the bus, which is part of the objectives of the controlled departure, can permit the bus itself, without stopping, to clear the intersection, and creating queues and traffic jam or car delays. The speed adjustment is among the prioritization techniques (Wu et al., 2016).

Among the techniques used in order to allocate the priority based on the controlled departure, we can denominate the use of semaphore control method, which is based on two operation modes: the controlled and the immediate departure. The decision takes into consideration not only the public transport but also the delay that car passengers may encounter with the bus priority allocation, thus it seeks complete efficiency and balance for the transport system as a whole (Koehler and Kraus, 2006).

The used method of holding up the bus for longer at the bus stop even though the boarding (embarking/alighting) has finished might seem unnecessary and a cause of delay. However, examining the whole process, we conclude that the late departure results in lowering the overall costs of the intersection by reducing or preventing stops. Besides, there is a maximum allowed holding time that needs to be respected so that the schedule is not violated and takes into consideration if the bus is ahead of its schedule, then its retention might be helpful to adjust its timing (Zolfaghari et al., 2004).

\subsection{Lessons learned}

The traffic encounters several issues on the daily basis and the lack of efficient management and the wrong bus stop design and location can worsen the daily commuting. These problems might require some small adjustments on the microscopic level, like a bus stop or a corridor, which can have a positive influence on the macroscopic level of the transportation system.

The prioritization systems depend on different involved parties like municipalities, economic statue and bus operators. These factors have a high influence on the type of the priority that can be implemented within the available infrastructure. Sometimes solutions such as TSP system or predictive traffic controller are not feasible due to physical or financial constraints.

Thus, this paper aims to provide a reasonable and applicable priority granting solution for the bus service that shall be tested on the chosen corridor.

\section{The corridor investigation}

As the city of Budapest grew up, several districts began to have a high residential concentration, such as the district XV (Rákospalota) and the district XIV (Zugló). Thus, a high number of daily commuters are present in this area varying between 74400 pax/day and 18700 pax/day according to the data provided by the transport model 207 by BKK (Budapesti Közlekedési Központ). Even though a high number and frequent buses are present on the corridor between the main intercity and international railway terminal in Budapest "Keleti Pályaudvar" and the previously mentioned residential areas, this corridor presents the highest number of commuters. Physically, in different parts of the corridor, the roads cannot be changed either by widening or by adding bus lane.

\subsection{GPS vehicle track measurement}

The examination of the bus circulation through GPS tracking is realized using the OsmAnd Application, which works offline and has a tracking record plug-in. It tracks 
the coordinates (latitude and longitude), the speed, the exact time, the elevation in each point, the chosen time step for this measurement is $5 \mathrm{sec}$, this helps have more accurate and precise information. These data are then saved as (.gpx) file, exported to Excel (.xlsx) file and analyzed.

The data collection was made for the bus line 7 on a weekday during the morning peak on Thursday 21 March 2019 between 7 am and $9 \mathrm{am}$. The measurement was made on two trips departing from Keleti Pályaudvar to Fö tér and back to the departure station.

Some important information was calculated and summarized in Table 1:

- the full time: is the time between the last door opening and the first door closing;

- the boarding/alighting time: the time between opening the doors until the majority of the passengers get on the bus;

- the loss time: is the time during which the speed of the vehicle is less than $5 \mathrm{~km} / \mathrm{h}$;

- the running time: full time minus the boarding time.

The estimated total journey time given by BKK FUTÁR is $23 \mathrm{~min}$, which is almost the same as the one towards Fö tér, considering the loss time, it represents $32 \%$ of the total journey time.

For the case of the journey towards Keleti Pályaudvar, as seen in Table 1, the total travel time is higher than expected and there was no accident or emergency. More than half of the whole time of the journey, the speed was less than $5 \mathrm{~km} / \mathrm{h}$, this results in big fuel consumption and low-quality service. The full time is $43 \mathrm{~min} 41 \mathrm{sec}$, while the loss time is $31 \mathrm{~min} 50 \mathrm{sec}$ representing $73 \%$ of the full journey time.

An analysis of the speed was then realized for a better understanding of the measurement, given the total travel distance on way is $7.86 \mathrm{~km}$. Some important features were calculated, as seen in Table 2:

- The overall average speed: it is the ratio of the full distance to the full time

- The moving average speed: is the ratio of the full distance to the running time of the vehicle

Table 1 Data analysis of the time measurements of the bus

\begin{tabular}{lcc}
\hline & To Fö tér & To Keleti Pályaudvar \\
\hline The full time & $21 \mathrm{~min} 2 \mathrm{sec}$ & $43 \mathrm{~min} 41 \mathrm{sec}$ \\
The boarding/alighting time & $1 \mathrm{~min} 50 \mathrm{sec}$ & $2 \mathrm{~min} 28 \mathrm{sec}$ \\
Time when speed $<5 \mathrm{~km} / \mathrm{h}$ & $8 \mathrm{~min} 37 \mathrm{sec}$ & $34 \mathrm{~min} 18 \mathrm{sec}$ \\
The loss time & $6 \mathrm{~min} 47 \mathrm{sec}$ & $31 \mathrm{~min} 50 \mathrm{sec}$ \\
The running time & $19 \mathrm{~min} 21 \mathrm{sec}$ & $41 \mathrm{~min} 13 \mathrm{sec}$ \\
\hline
\end{tabular}

Table 2 Data analysis of the speed of the bus

\begin{tabular}{lcc}
\hline & To Fö tér & To Keleti Pályaudvar \\
\hline The overall average speed & $22.421 \mathrm{~km} / \mathrm{h}$ & $10.796 \mathrm{~km} / \mathrm{h}$ \\
The moving average speed & $24.562 \mathrm{~km} / \mathrm{h}$ & $11.442 \mathrm{~km} / \mathrm{h}$ \\
\hline
\end{tabular}

The speed measurement is given in Table 2 .

If we consider the total distance $7.86 \mathrm{~km}$ between the two stops and the estimated time of $23 \mathrm{~min}$ (given by BKK FUTÁR), the average speed shall be $20.5 \mathrm{~km} / \mathrm{h}$. Here also, the journey towards Keleti Pályaudvar presents a much lower speed.

The analysis of the recorded data using OsmAnd for both directions are used in order to draw the diagrams of the speed variation function of the distance traveled by the vehicle are demonstrated in Fig. 2.

The speed limit in the urban zones in Budapest is $50 \mathrm{~km} / \mathrm{h}$, which has been violated in both ways. In the case of the return journey, we see that the driver tries to catch up after the long time wasted during the journey due to the traffic.

\subsection{Vehicle occupancy and time parameters measurements}

The second measurement is realized in the two stops separately, twice in Fö tér and twice in Keleti Pályaudvar, it aims to check precisely the number of passengers across the section and specify the time parameters such as dwell, running and boarding times which can characterize the punctuality of the buses as well as the number of boarding/ alighting passengers and the pattern category.

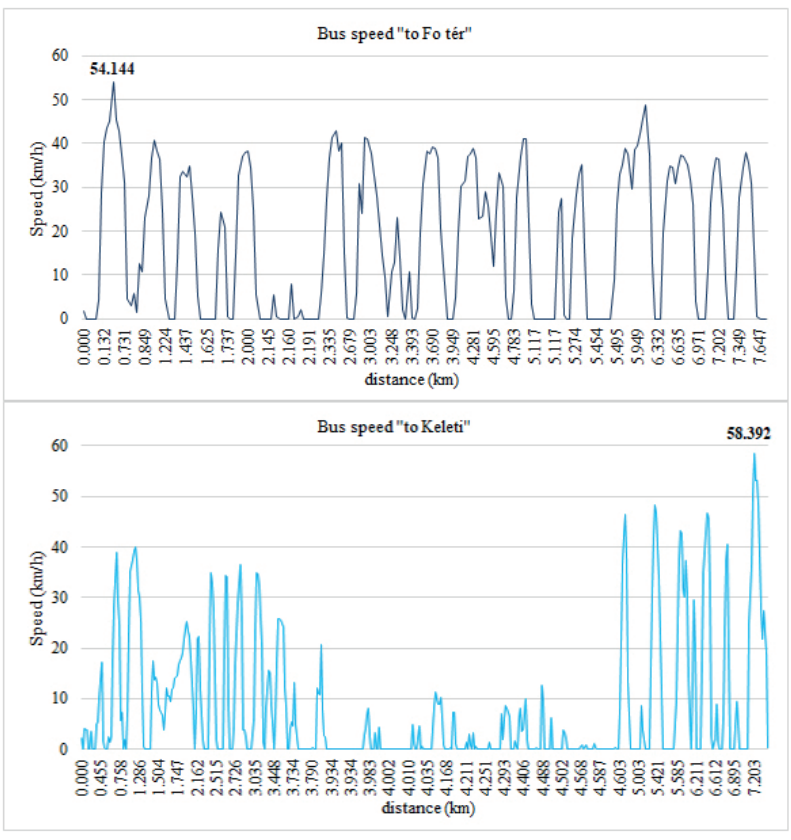

Fig. 2 Speed variation of bus line7 on both ways (Excel) 


\begin{tabular}{|c|c|c|c|c|c|c|c|c|}
\hline \multicolumn{2}{|l|}{ Station: } \\
\cline { 5 - 8 } $\mathrm{N}^{\circ}$ & Line & $\begin{array}{c}\text { Type of } \\
\text { Bus }\end{array}$ & Arrival & $\begin{array}{c}\text { End of boarding/ } \\
\text { alighting }\end{array}$ & $\begin{array}{c}\text { Door } \\
\text { closing }\end{array}$ & $\begin{array}{c}\text { Departure from } \\
\text { traffic light }\end{array}$ & $\begin{array}{c}\text { Pattern } \\
\text { category }\end{array}$ & $\begin{array}{c}\text { Number of } \\
\text { passengers }\end{array}$ \\
\hline 1 & & & & & & & & \\
\hline 2 & & & & & & & & \\
\hline 3 & & & & & & & & \\
\hline
\end{tabular}

Fig. 3 Sample of the vehicle occupancy and time parameters measurement

Table 3 Data analysis of buses per station

\begin{tabular}{|c|c|c|c|c|c|c|}
\hline \multirow{3}{*}{$\begin{array}{l}\text { Peak hour } \\
\text { Station } \\
\text { Direction }\end{array}$} & & & \multicolumn{2}{|c|}{ Morning peak } & \multicolumn{2}{|c|}{ Evening peak } \\
\hline & & & \multicolumn{2}{|c|}{ Fö tér } & \multicolumn{2}{|c|}{ Keleti Pályaudvar } \\
\hline & & & To Keleti (WS) & From Keleti (NE) & To Fö tér (NE) & From Fö tér (WS) \\
\hline Time & & & $7 \mathrm{~h}-8 \mathrm{~h}$ & $8 h-9 h$ & $16 h-17 h$ & $17 \mathrm{~h}-18 \mathrm{~h}$ \\
\hline \multirow{4}{*}{ 1st measurement } & $\mathrm{S}$ buses & 41 & 33 & 33 & 33 & \\
\hline & Average headway & $01: 25$ & $01: 49$ & 01:46 & $01: 44$ & \\
\hline & \multirow{2}{*}{ Passen-gers } & Sum of arrivals & 781 & 542 & 1615 & 1574 \\
\hline & & Sum of departures & 1294 & 388 & 2078 & 1588 \\
\hline \multirow{4}{*}{ 2nd measurement } & $\mathrm{S}$ buses & 50 & 30 & 35 & 34 & \\
\hline & Average headway & 01:08 & $01: 59$ & 01:43 & $01: 48$ & \\
\hline & \multirow{2}{*}{ Passen-gers } & Sum of arrivals & 1005 & 473 & 1698 & 1722 \\
\hline & & Sum of departures & 1702 & 385 & 2198 & 1444 \\
\hline \multirow{4}{*}{ Average } & $\mathrm{S}$ buses & 46 & 32 & 34 & 34 & \\
\hline & Average headway & $01: 16$ & $01: 54$ & $01: 45$ & 01:46 & \\
\hline & \multirow{2}{*}{ Passen-gers } & Sum of arrivals & 893 & 508 & 1657 & 1648 \\
\hline & & Sum of departures & 1498 & 387 & 2138 & 1516 \\
\hline
\end{tabular}

The abbreviations of NE and WS are used in order to simplify the description of the data according to the stop:

- NE: North-East

- WS: West-South

Two measurements were realized in each stop for each direction during the morning peak and the evening peak hours in two different weekdays, so as completely eight measurements were done. The first measurement was made on Wednesday 20 March 2019 and the second measurement was made on Thursday 4 April 2019.

The bus lines analyzed are: 108E, 7E, 8E, 133E and 7, the sample of the gathered information are summarized in Fig. 3.

The door closure is usually 3 to $5 \mathrm{sec}$ after the end of boarding/alighting and the departure is usually 3 to $5 \mathrm{sec}$ after the door closure. However, this differs if traffic signals exist and depends on the driver's behavior:

- The driver might drive for a few meters, the doors are closed and the bus waits for the traffic signal

- The driver might wait at the stop while doors are open until the traffic light changes then doors are closed and the bus departs.
The information gathered as seen in Fig. 3 are analyzed and summarized in Table 3 for the two measurements for the two-way journeys.

A high number of passengers and buses was noted in the corridor, as seen in Table 3, and in order to understand the passengers' flow in the corridor, the data of the average between the two measurements, are illustrated in the Fig. 4.

People are more likely to commute from the residential areas near Fő tér towards the more busy centre, Keleti Pályaudvar, for work, universities and daily activities as noticed in the morning peak and come back in the afternoon, as shown by the passengers' flow in Fig. 4.
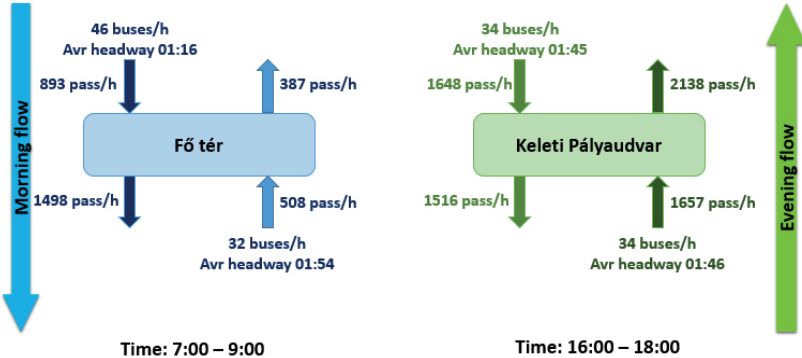

Fig. 4 Passengers' flow in the two bus stops 
The bus stops of Keleti is busier in both directions than the stops of Fö ter with a range of carried passengers not less than 1516 passenger/hour to more than 2000 passenger/hour. The buses in the busy directions were very crowded despite their high frequency.

In the morning peak, the average pattern category in Fö tér in both directions is 1 for the arrivals, meaning the number of passengers less than 21 passengers while the average category departure pattern is 2 , between 22 and 41 passengers. In some cases, the maximum passengers pattern reaches category 4, meaning between 53 and 83 passengers.

Which means the buses are quite empty.

In the evening peak, the bus stop of Keleti Pályaudvar is busier with average passengers category pattern is 3, between 42 and 62 passengers and the maximum is usually reached, i.e., category 5, between 84 and 103 passengers and the buses are super full.

For a better understanding of the different correlations, the influences of the parameters on each other and the significance of the diverse tests as well as the significance of the tests were analyzed using the advanced statistical analysis tool, SPSS.

The bivariate correlations determined using SPSS between the different parameters, which gives idea about the influence of each parameter on the other ones, are summarized in Table 4.
The Pearson correlation value, the $r$-value, indicates the linear association between two variables. The sign of this coefficient shows the relationship's direction, and its strength is determined by how close it is to the one of the two extremes (Cohen, 1988).

The number of passenger arrival and departure are highly positively correlated with the average number of passengers based on $n=289,(r=0.931>5)$ and $(r=0.942>5)$ respectively, which is totally normal.

The dwell time is highly correlated with the end of boarding/alighting time $(r=0.651>5)$ and the number of passengers arrival $(r=0.502>5)$ but moderately correlated with the number of passengers departure $(3<r=0.431<5)$ and the average dwell time $(3<r=0.497<5)$. Thus, the dwelling is mostly because of the alighting time, which is due to the number of passengers' arrival.

The realized analysis are based on measurement both at the stops defining the corridor and another GPS based measurement checking the bus's behavior. This examination presents a preliminary analysis of the bus service and its issues. These measurements shall be used in Section 5 in order to deeply analyze the dwell time, its impact and the prioritization method as well as the benefits it shall bring to the transport system through a coded program using GNU Octave.

Table 4 Bivariate Correlation (SPSS)

\begin{tabular}{|c|c|c|c|c|c|}
\hline & & Average passenger & Dwell time & $\mathrm{N}^{\circ}$ pass arrival & $\mathrm{N}^{\circ}$ pass departure \\
\hline \multirow{3}{*}{ Average passenger } & Pearson Correlation & 1 & $0.497^{* *}$ & $0.931 * *$ & $0.942 * *$ \\
\hline & Sig. (2-tailed) & & 0.000 & 0.000 & 0.000 \\
\hline & $\mathrm{N}$ & 289 & 287 & 289 & 289 \\
\hline \multirow{3}{*}{ Dwell time } & Pearson Correlation & $0.497^{* *}$ & 1 & $0.502 * *$ & $0.431 * *$ \\
\hline & Sig. (2-tailed) & 0.000 & & 0.000 & 0.000 \\
\hline & $\mathrm{N}$ & 287 & 287 & 287 & 287 \\
\hline \multirow{3}{*}{ Door closing } & Pearson Correlation & $0.146^{*}$ & $0.320 * *$ & $0.146^{*}$ & $0.128^{*}$ \\
\hline & Sig. (2-tailed) & 0.013 & 0.000 & 0.013 & 0.030 \\
\hline & $\mathrm{N}$ & 289 & 287 & 289 & 289 \\
\hline \multirow{3}{*}{ End of boarding/ alighting } & Pearson Correlation & $0.475^{* *}$ & $0.651^{* *}$ & $0.424^{* *}$ & $0.464^{* *}$ \\
\hline & Sig. (2-tailed) & 0.000 & 0.000 & 0.000 & 0.000 \\
\hline & $\mathrm{N}$ & 287 & 287 & 287 & 287 \\
\hline \multirow{3}{*}{$\mathrm{N}^{\circ}$ passengers arrival } & Pearson Correlation & $0.931^{* *}$ & $0.502 * *$ & 1 & $0.754 * *$ \\
\hline & Sig. (2-tailed) & 0.000 & 0.000 & & 0.000 \\
\hline & $\mathrm{N}$ & 289 & 287 & 289 & 289 \\
\hline \multirow{3}{*}{$\mathrm{N}^{\circ}$ passengers departure } & Pearson Correlation & $0.942 * *$ & $0.431 * *$ & $0.754^{* *}$ & 1 \\
\hline & Sig. (2-tailed) & 0.000 & 0.000 & 0.000 & \\
\hline & $\mathrm{N}$ & 289 & 287 & 289 & 289 \\
\hline
\end{tabular}

**Correlation is significant at the 0.01 level (2-tailed); ${ }^{*}$ Correlation is significant at the 0.05 level (2-tailed) 


\section{Dwell time optimization and bus priority allocation}

In the case of Keleti Pályaudvar stops (WS and NE), there is no special platform for the bus stops and there is a presence of traffic lights, so, one or multiple buses need to occupy a lane and while dwelling in the stop, the traffic is disturbed. As studied in (Gu et al., 2014), the presence of a bus creates a bottleneck situation and in the case of Keleti stops, they are located on the downstream of the intersection, which creates more issues as studied in (Transit Cooperative Research Program, 1996).

\subsection{The impact of the dwelling bus on the car delays}

The assumptions in the dwell time analysis are the following:

- The analysis is made inspired by the work in (Gu et al., 2014)

- The study is made based on measuring the impact of the existence of bus in the bus stop in the case where there is no special curbside.

- The above has more effect on the lane where the bus is present.

- The used abbreviations are:

- $d$ : distance of the bus stop to the intersection

- $q$ : the stationary inflow capacity of freely flowing cars

- $Q$ : the capacity of the road

- $Q_{B}$ : The bottleneck capacity

- $C_{0}$ : cycle time

- $G$ : the fixed green time in each $C_{0}$

- $w$ : the backward wave speed of the car queue

- $g$ : the green ratio, as in Eq. (1):

$g=G / C_{0}$
- $t_{e}$ : the time needed for the queue to be dissipated, as Eq. (2):

$$
t_{e}=\left((1-g) C_{0} q\right) /(Q-q)
$$

The impact of the bus is analyzed in the time interval of:

- The time arrival of the bus: $t_{a}$

- The time in the stop: $S$

The used formulas replicate the theory of kinematic wave theory of highway traffic presented by (Ni, 2016) based on (Lighthill and Whitham, 1955) all different scenarios have been realized and for each scenarios stated by all the cases shown in Fig. 5, the delay would be calculated. The car delays are measured within one or two cycles.

The delay is calculated as the difference between the curve of the cars' flow without the presence of a bus and the one determining the affected flow of cars when a bus is present in the bus stop, as shown with the grey part in Fig. 6, which presents an example of the method used.

The interesting cumulative count curve, the orange one seen in Fig. 6, denoted as Y, concerns the discharge flows of the vehicles that are affected by the bus present and dwelling in the stop. The discharge is affected even after the bus starts moving as studied with the kinematic waves of the traffic flow, the bus's presence may have longer effect beyond two cycles.

For each cycle $C_{0}$, the vehicles' discharge without the presence of a bus YY, is as presented in Eq. (3):

$$
Y Y(t)=\left\{\begin{array}{c}
\text { Qtift }\left[0, t_{e}\right] \\
q t+(Q-q) t_{e} i f t \epsilon\left[t_{e}, g C_{0}\right] . \\
q g C_{0}+(Q-q) t_{e} i f t \epsilon\left[g C_{0}, C_{0}\right]
\end{array} .\right.
$$

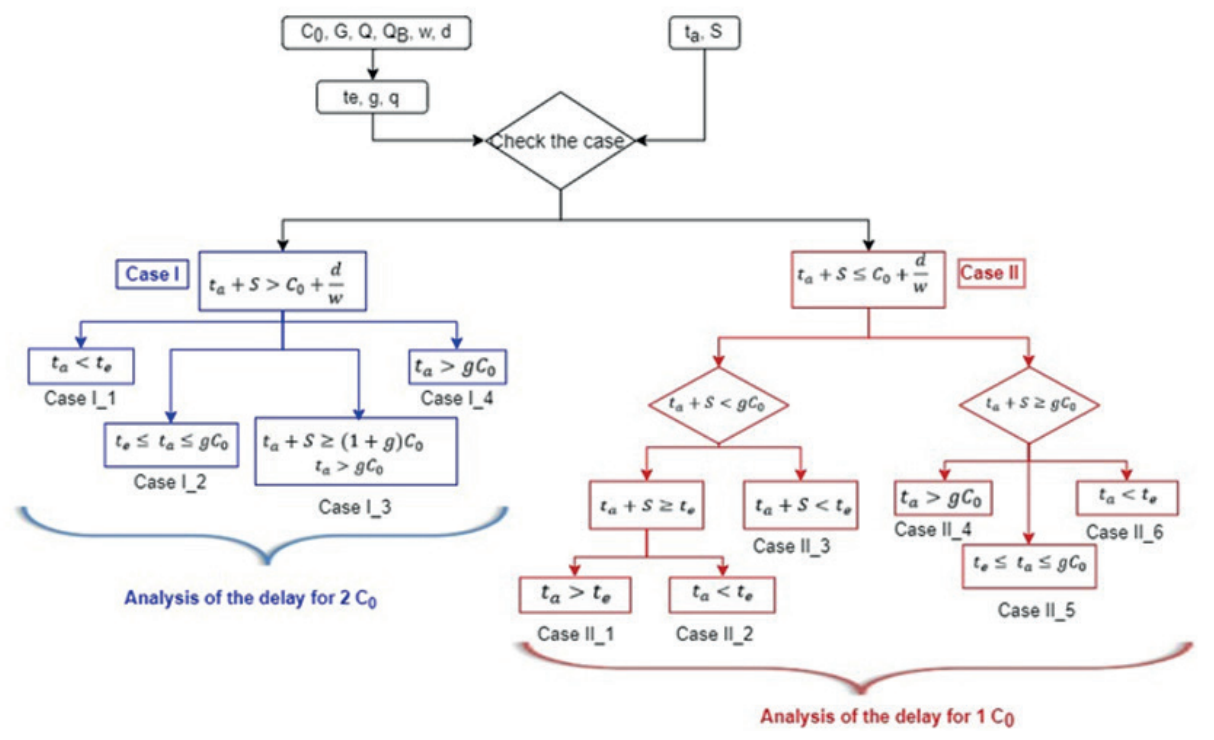

Fig. 5 Diagram of scenarios used to calculate the delay 


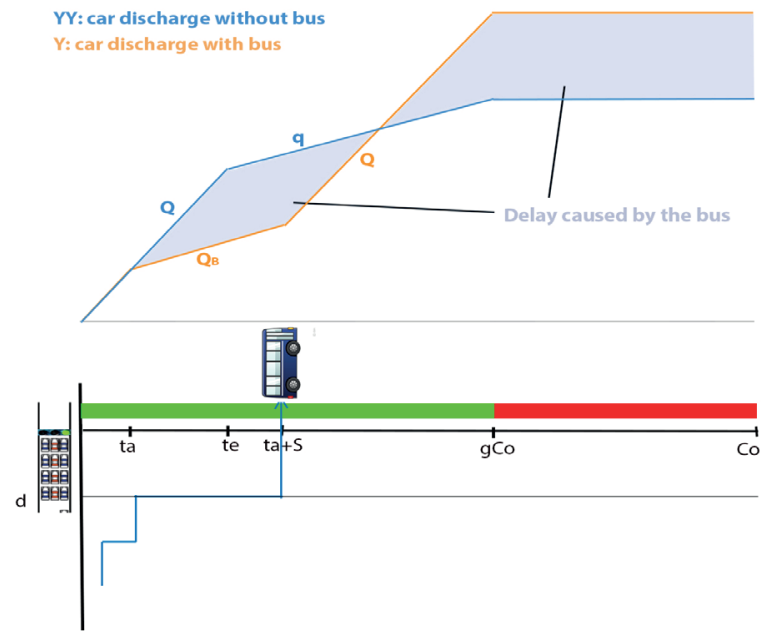

Fig. 6 The impact of the bus arrival and dwell time on the car delays

When the bus arrives, $t_{a}$, the cars that were queued before the traffic lights turn to green, which is assumed to be the 0 point here, are discharged with a lower flow rate, $Q_{B}$ into the intersection. If the bus manages to go through the intersection before $g C_{0}$, before the end of the green time, it does not create a long queue. After the bus leaves, after $t_{a}+S$, the vehicles are dissipated and the flow of the discharge recovers to $Q$.

The delay of the vehicles created due to the presence of the bus is then calculated according to Eq. (4), where $k$ is an integer:

$$
\text { delay }=\int_{0}^{k C_{0}}(Y-Y Y) d t
$$

The delay calculated can be negative or positive, if it is positive, it means the bus creates delay over the entire cycle length. If it is negative, this means that the bus has a small effect but as seen from the entire studied period, the effect does not affect the cars as seen analyzing the whole cycle for a small duration.

In every scenario, the following features are used:

- $Q=1 \mathrm{veh} / \mathrm{sec}$

- $q=0.4 \sec$ (under-saturated situation)

- $Q_{B}=0.5 \mathrm{veh} / \mathrm{sec}$

- $d=100 \mathrm{~m}$

- $w=6.22 \mathrm{~m} / \mathrm{s}$ (from the measurement)

- $C_{0}=90 \mathrm{sec}$ (measured from the traffic lights)

- $G=54 \mathrm{sec}$ (measured from the traffic lights)

All the discharge curves using the collected data and the iterative model with Octave are summarized in Fig. 7, where the bold blue line represents the normal car flow with no bus, the curve Y. The cases are sorted according to the different cases mentioned in Fig. 5.

In Case II, all scenarios, $t_{a}+S$ are within the $1^{\text {st }} C_{0}$, so the bus departs in the second green time and doesn't create extra queues in the $2^{\text {nd }}$ cycle:

Case II_1: the bus comes and leaves within the green light, thus the time in the stop, $S$, is small and the bus does not create a high delay, slightly after $t_{a}+S$, the bus doesn't affect the vehicles anymore and leaves the intersection.

Case II_2: the bus comes and leaves during the green light, the longer the bus stays in the stop, the higher the delay is.

Case II_3: the bus came before the existing queue was fully dissipated and dwelled for a small period, then it left when it was still green and the delay affected the whole cycle and beyond.

Case II_4: As the bus comes and its time in the stop is all during the red light and after the existing queue is dissipated, the bus does not create the queue itself, as already the queue is due to the red lights, thus the two curves are similar, with and without the bus. This case does not create delay for the vehicles

Case II_5: The buses coming after the queue is dissipated but while the lights are green, therefore, the bus creates a relatively small delay for the vehicles coming from the downstream intersection

Case II_6: The bus coming during the green time, before the queue is dissipated and dwelling until the lights are red, create high delays for the existing queue upstream and vehicles coming from downstream intersection

Case I, here the bus comes and stays until the second green time

Case I_4: the bus comes during the red time and leaves within the $2^{\text {nd }}$ green time, it does not create queues itself as the lights are already red, yet it creates some delay during the $2^{\text {nd }}$ green and the faster it leaves the stop, the lower the delay is as the bus stays less in the green time.

Case I_3: the bus comes in the red light of the $1^{\text {st }}$ cycle and stays until the second red time, which creates high delay and traffic perturbance.

\subsection{Analysis of the bus priority granting}

For a dense urban area, the improvement of the bus service should take into consideration the several variables and might be realized in developing and optimizing the total bus stop time models. (Arhin et al., 2016)

The optimization of the dwell time does not mean the optimization of the bus services as many other factors 


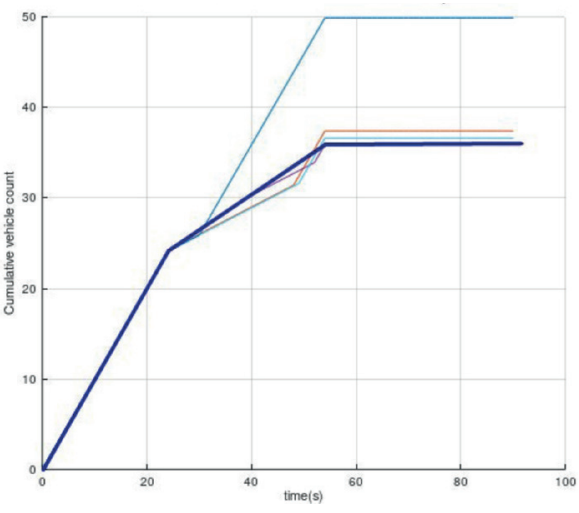

(a)

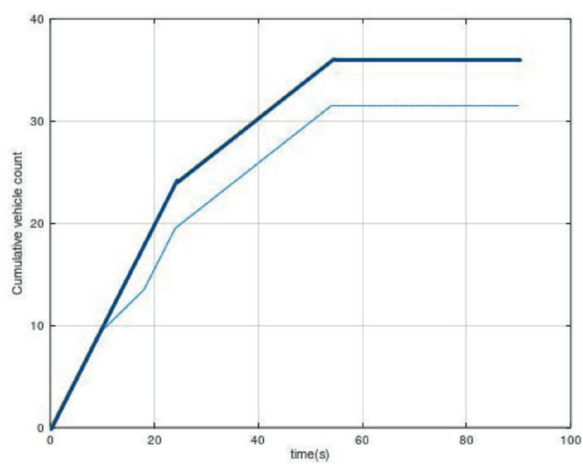

(c)

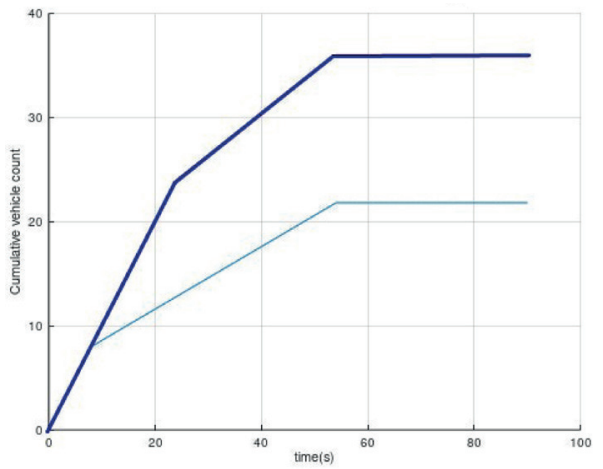

(e)

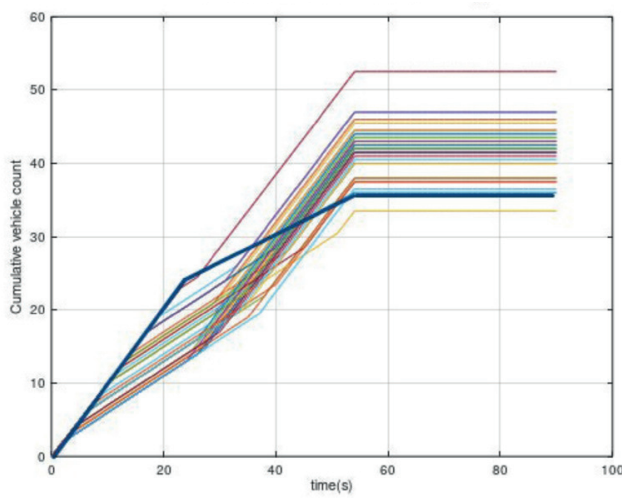

(b)

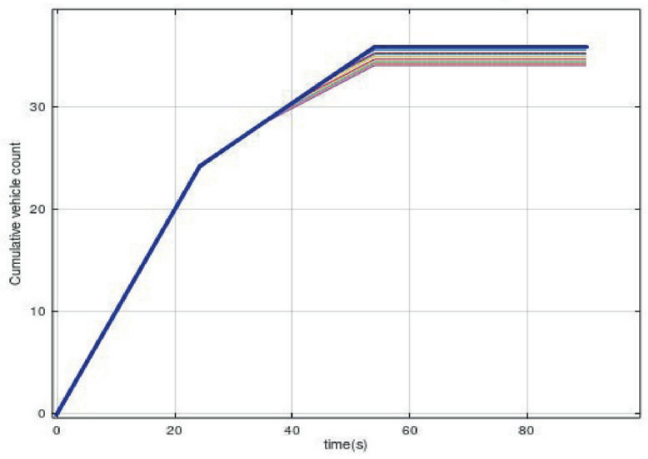

(d)

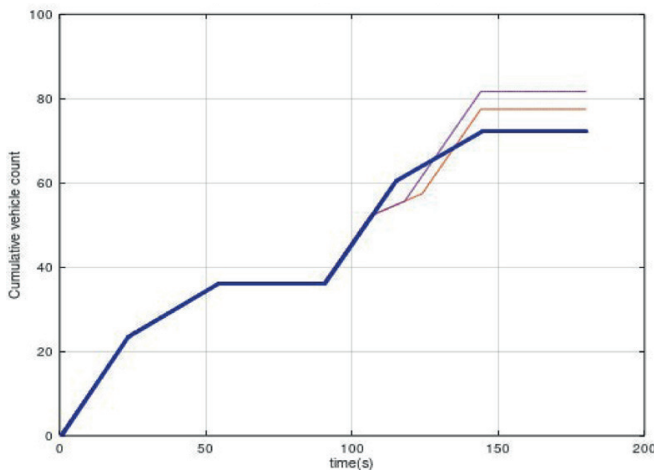

(f)

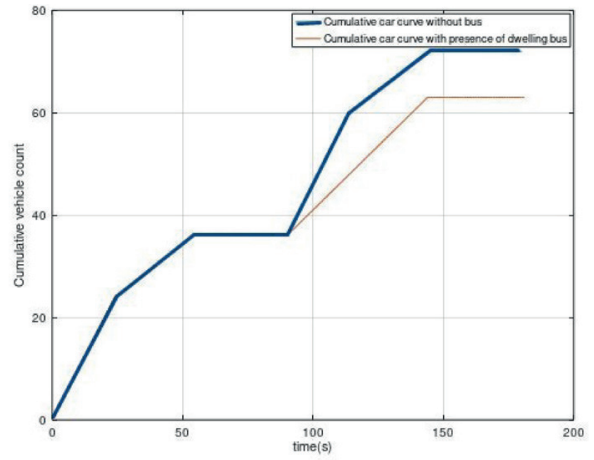

(g)

Fig. 7 Discharge flow curves sorted by case (Octave); (a) Impact of dwelling bus on car delays Case II1 ; (b) Impact of dwelling bus on car delays Case II2; (c) Impact of dwelling bus on car delays Case II3; (d) Impact of dwelling bus on car delays Case II5; (e) Impact of dwelling bus on car delays Case II6; (f) Impact of dwelling bus on car delays Case I4; (g) Impact of dwelling bus on car delays Case I3 
interfere in this analysis. Thus, the overall study of the parameters and priority allocation are realized. The following assumptions are used:

- After the bus is ready to leave at the time $T_{c}$ it can have either an Immediate Departure (ID) or a Controlled Departure (CD).

- The speed is assumed to be constant in each scenario and if it is needed to be changed, this is taken into consideration.

- The priority allocation takes into consideration the maximum green light extension and the maximum holding time of the bus in the bus stop for the case of the controlled departure (CD) for the benefits of the road users.

The operation of the system begins after the doors' closure and it is ready for the departure, $T_{c}$, it is measured from the beginning of the cycle, i.e. the beginning of green time. The decision is made according to the interval in which $T_{c}$ is located. The scenarios are delimited by $\mathrm{B}_{1}, \mathrm{C}$, $\mathrm{D}, \mathrm{A}$ and $\mathrm{B}_{2}$ that depend on the speed of the bus with which it can go, the cars flow, saturation flow, the average car length, the distance of the bus stop to the intersection and the green and red time. Then the bus, the cars delays and the green time extension are measured using the iterative model realized with Octave according to the scenarios. The scenarios and the priority allocation used are detailed in the following diagram in Fig. 8.
With the beginning of the red time, the bus is usually estimated to face a delay, with the CD method. The aim is to minimize this delay with considering that holding the bus means decreasing the waiting time for the traffic light, and compromising it by increasing the time in the stop to serve it for longer, this also decreases the fuel consumption and the number of bus stoppings. The decisions taken in each scenario is demonstrated in Fig. 8.

A sample of the calculated green time extension, bus delays and car delay according to the scenarios and a comparison with the normal car delays without bus priority using the code is summarized in Table 5, all the data are in seconds.

With the scenario $C$, the bus would proceed without changing its speed or can be going with a higher speed as the light is already green and the cars have been discharged.

In scenario $\mathrm{D}$, without exceeding the maximum green time, the bus cannot go through the intersection without facing a delay.

The scenario $B$ is divided into two scenarios, $B_{1}$ and $B_{2}$, here an adjustment in the speed is required. In the first part $\mathrm{B}_{1}$, the light is green so the bus faces delay as queues are being cleared after the end of the previous red time. In the second part, $\mathrm{B}_{2}$, the bus would face higher delays because of the queue created due to the red time, thus the discharge of the bus is realized after the discharge of the vehicle queue in front of it.

With the scenario A, the bus itself is clearing the intersection by adjusting the speed or by the holding time.

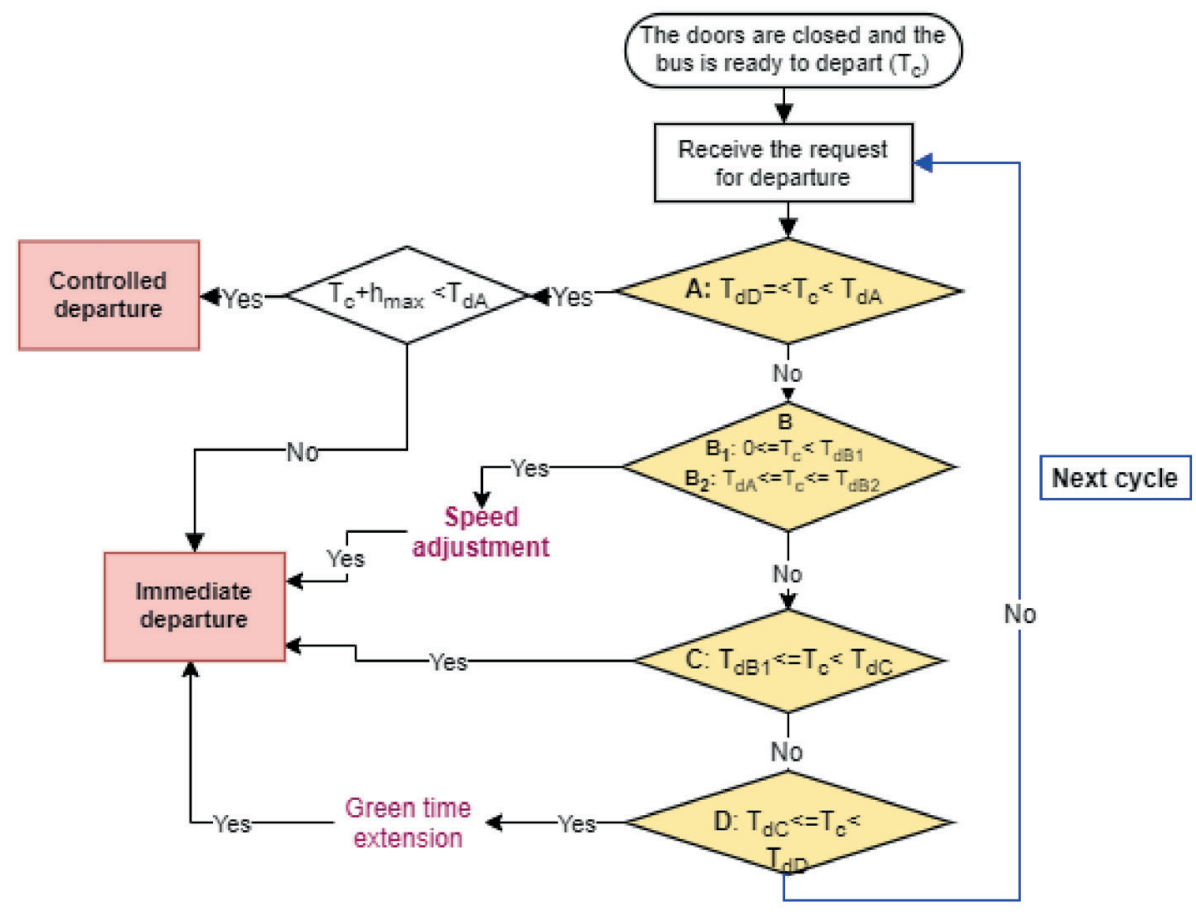

Fig. 8 The diagram of bus priority allocation 
Table 5 Analysis of the cars and bus delays with the allocated priority

\begin{tabular}{cccccc}
\hline$T_{c}$ & $D_{\text {bus }}$ & $D_{\text {car }}$ & $t_{\text {ext }}$ & Scenario & $\begin{array}{c}D_{c a r}(\mathrm{~s}) \text { previously } \\
\text { measured }\end{array}$ \\
\hline 1 & 79.813 & 11.0112 & 0 & $\mathrm{~B} 1$ & 70 \\
40 & 0 & 11.0112 & 0 & $\mathrm{C}$ & 206.5 \\
54 & 0 & 5.7317 & 9.00901 & $\mathrm{D}$ & 79.2 \\
57 & 22.3 & 11.0112 & 0 & $\mathrm{~A}$ & 85 \\
80 & 244.46 & 11.0112 & 0 & $\mathrm{~B} 2$ & 73.5 \\
\hline
\end{tabular}

\section{Conclusion and discussion}

The impact of the dwelling bus on the traffic is the main function of the time of the bus arrival and the dwell time in the stop. The priority granting guarantees the minimum delays for both buses and vehicles in the two branches and the buses, while keeping the smooth evacuation of the cars. In this work, each bus arrival is counted separately in cycle time and the impact of each one is separate. Thus, in the reality, the bus benching can affect both the vehicles and the buses' circulation. While in this presented work only

\section{References}

Ahmed, B. (2014) "Exploring New Bus Priority Methods at Isolated Vehicle Actuated Junctions", Transportation Research Procedia, 4, pp. 391-406.

https://doi.org/10.1016/j.trpro.2014.11.030

Arhin, S., Noel, E., Anderson, M. F., Williams, L., Ribisso, A., Stinson, R. (2016) "Optimization of transit total bus stop time models", Journal of Traffic and Transportation Engineering (English Edition), 3(2), pp. 146-153.

https://doi.org/10.1016/j.jtte.2015.07.001

Budapesti Közlekedési Központ (BKK) (2013). "Balázs Mór- terv. Budapest mobilitási terve 2014-2030" (BALÁZS MÓR plan Budapest Transport development strategy 2014-2030 BMT), [pdf] Budapesti Közlekedési Központ, Budapest, Hungary. Available at: https://bkk. hu/downloads/6125/61biqhFm_Kbl-YOV6_X11A==[Accessed: 15 November 2019] (in Hungarian)

Boudhrioua, S., Shatanawi, M. (2021) "Implementation of Absolute Priority in a Predictive Traffic Actuation Schemes", Periodica Polytechnica Transportation Engineering, 49(2), pp. 182-188. https://doi.org/10.3311/PPtr.14191

Cohen, J. (1988) "Statistical Power Analysis for the Behavioral Sciences", Lawrence Erlbaum Associates, Mahwah, NJ, USA. https://doi.org/10.4324/9780203771587

Denke, Z. (2017) "Budapest public transport system and its organization", presented at BKK Centre for Budapest Transport, Budapest, Hungary, Apr. 25, 2017.

Gu, W., Gayah, V. V., Cassidy, M. J., Saade, N. (2014) "On the impacts of bus stops near signalized intersections: Models of car and bus delays", Transportation Research Part B: Methodological, 68, pp. 123-140. https://doi.org/10.1016/j.trb.2014.06.001 the effect of one bus on the present vehicles in the same lane and the overall car delays in the intersection is analyzed.

Moreover, the position of the bus stop has a high effect on the traffic situation, thus an analysis of this matter might also prevent delays for vehicles if incorporated with the bus prioritization system.

The prioritization system evaluated is the controlled departure with consideration of the non-violation of the maximum holding time, the maximum green time extension and the maximum red time in the branches of the intersection where the bus stop exists. The iterative model coded with Octave checks all scenarios of the effect of whether holding the bus after it is ready to go is necessary, then the delay of the cars and the bus are both calculated.

The prioritization method reveals the gain in car delays in comparison with no priority system and relatively short bus delays depending on the time the bus shall leave the intersection. The controlled departure goes beyond gaining in time loss to reach fuel consumption, energy efficiency, easier driving and smooth traffic.

Guler, S. I., Gayah, V. V., Menendez, M. (2015) "Providing Bus Priority at Signalized Intersections with Single-lane Approaches", Transportation Research Procedia, 9, pp. 225-245. https://doi.org/10.1016/j.trpro.2015.07.013

Koehler, L. A., Kraus Jr., W. (2006) "A controlled departure method for bus priority operation", IFAC Proceedings Volumes, 39(12), pp. 397-402. https://doi.org/10.3182/20060829-3-NL-2908.00069

Kózel, M. (2017) "Public transport prioritization - Introduction of BRT", BMEKOKUM206 SH Transport operation course, EconomicsBudapest University of Technology and Economics, Budapest, Hungary, unpublished.

Lighthill, M. J., Whitham, G. B. (1955) "On kinematic waves II. A theory of traffic flow on long crowded roads", Proceedings of the Royal Society of London. Series A: Mathematical and Physical Sciences, 229(1178), pp. 317-345. https://doi.org/10.1098/rspa.1955.0089

Liu, Z., Jian, M. (2019) "Traffic impacts analysis of bus stops near signalized intersections based on an optimal velocity model", Advances in Mechanical Engineering, 11(5), pp. 1-11. https://doi.org/10.1177/1687814019848272

Muñoz, J. C., Cortés, C. E., Giesen, R., Sáez, D., Delgado, F., Valencia, F., Cipriano, A. (2013) "Comparison of dynamic control strategies for transit operations", Transportation Research Part C: Emerging Technologies, 28, pp. 101-113. https://doi.org/10.1016/j.trc.2012.12.010

Nesmachnow, S., Massobrio, R., Arreche, E., Mumford, C., Olivera, A. C., Vidal, P. J., Tchernykh, A. (2019) "Traffic lights synchronization for Bus Rapid Transit using a parallel evolutionary algorithm", International Journal of Transportation Science and Technology, 8(1), pp. 53-67.

https://doi.org/10.1016/j.ijtst.2018.10.002 
Ni, D. (2016) "Traffic Flow Characteristics I", In: Traffic Flow Theory: Characteristics, Experimental Methods, and Numerical Techniques, Butterworth-Heinemann, Oxford, UK, pp. 19-35. https://doi.org/10.1016/B978-0-12-804134-5.00002-7

Oliveira-Neto, F. M., Loureiro, C. F. G., Han, L. D. (2009) "Active and Passive Bus Priority Strategies in Mixed Traffic Arterials Controlled by SCOOT Adaptive Signal System: Assessment of Performance in Fortaleza, Brazil", Transportation Research Record: Journal of the Transportation Research Board, 2128(1), pp. 58-65. https://doi.org/10.3141/2128-06

Pojani, D., Stead, D. (2015) "Sustainable Urban Transport in the Developing World: Beyond Megacities", Sustainability, 7(6), pp. 7784-7805.

https://doi.org/10.3390/su7067784

Shaaban, K., Ghanim, M. (2018) "Evaluation of Transit Signal Priority Implementation for Bus Transit along a Major Arterial Using Microsimulation", Procedia Computer Science, 130, pp. 82-89. https://doi.org/10.1016/j.procs.2018.04.015
Transit Cooperative Research Program (1996) "Guidelines for the Location and Design of Bus Stops", National Academy Press, Washington, DC, USA, Rep. 19.

Wu, W., Ma, W., Long, K., Wang, Y. (2016) "Integrated optimization of bus priority operations in connected vehicle environment", Journal of Advanced Transportation, 50(8), pp. 1853-1869. https://doi.org/10.1002/atr.1433

Zolfaghari, S., Azizi, N., Jaber, M. Y. (2004) "A model for holding strategy in public transit systems with real-time information", International Journal of Transport Management, 2(2), pp. 99-110.

https://doi.org/10.1016/j.ijtm.2005.02.001 